\title{
POMC and NPY mRNA expression during development is increased in rat offspring brain from mothers fed with a high fat diet
}

\author{
Marianne Orlandini Klein a,b,*, Harry MacKay ${ }^{\mathrm{a}}$, Alexander Edwards ${ }^{\mathrm{a}}$, Su-Bin Park ${ }^{\mathrm{a}}$, \\ Ana Carolina Inhasz Kiss ${ }^{c}$, Luciano Freitas Felicio ${ }^{\mathrm{b}, \mathrm{d}}$, Alfonso Abizaid ${ }^{\mathrm{a} \text {,* }}$ \\ a Department of Neuroscience, Carleton University, Ottawa, ON, Canada \\ ${ }^{\mathrm{b}}$ Department of Pharmacology, Institute of Biomedical Science, University of São Paulo, São Paulo, SP, Brazil \\ ' Department of Physiology, São Paulo State University, Botucatu, SP, Brazil \\ ${ }^{\mathrm{d}}$ Department of Pathology, School of Veterinary Medicine, University of São Paulo, São Paulo, SP, Brazil
}

\section{A R T I C L E I N F O}

\section{Article history:}

Received 4 November 2016

Received in revised form 21 February 2017

Accepted 10 March 2017

Available online 18 March 2017

\section{Keywords:}

Hypothalamic development

Metabolic programing

Food intake control

Offspring development

Obesity

\begin{abstract}
A B S T R A C T
Developmental programing is influenced by perinatal nutrition and it has long-lasting impacts on adult metabolism in the offspring. In particular, maternal high fat diet has been associated with increased risk of obesity and metabolic disorders during adulthood in the descendants. These effects may be due to the effects of the high fat diet on the development of the systems that regulate food intake and energy balance in the offspring hypothalamus. The arcuate nucleus (ARC) may be a particularly sensitive region to it as this nucleus contains the POMC and AgRP/NPY neurons that integrate the melanocortin system. Thus, the aim of this study was to investigate the effects of maternal high fat diet during pregnancy on the transcription factors that regulate hypothalamic development in the offspring as a potential mechanism that may result in altered neuronal expression of POMC, NPY and/or AgRP. To this end, pregnant females exposed to high fat diet (60\% fat diet since day 0 of pregnancy) or standard rat chow were sacrificed on days 12, 14, 16 and 18 of gestation to obtain brains from their developing fetuses and examine the mRNA expression of transcription factors associated with the development of cells in the ARC. Results show that, while no changes in transcription factor expression between groups were observed, POMC and NPY mRNA expression were higher on embryonic day 18 in the high fat group. These results suggest that POMC and NPY expression are altered by in utero exposure to a high fat diet, but these changes in gene expression are not associated with changes in the expression of transcription factors known to determine the fate of ARC cells.
\end{abstract}

(c) 2017 ISDN. Published by Elsevier Ltd. All rights reserved.

\section{Introduction}

There is mounting evidence suggesting that maternal nutrition has a large impact on the systems that control the regulation of food intake and energy balance in their offspring, often predisposing them to obesity and metabolic disorders including type II diabetes, cardiovascular disease and metabolic syndrome (Barker, 2002; Poston, 2012; Samuelsson et al., 2008). In some rodent models exploring this phenomenon, females are exclusively fed a high fat diet during pregnancy and/or lactation, and descendants are allowed to grow until adulthood (Howie et al., 2013; Sun et al., 2012; Dearden and Balthaszar, 2014). Results from these studies show that offspring of mothers fed the high fat diet during preg-

\footnotetext{
* Corresponding authors at: Carleton University, Department of Neuroscience, 1125 Colonel By Drive, Room 329, Ottawa, ON, Canada K1S 5B6.

E-mail addresses: mah_klein@hotmail.com (M.O. Klein), alfonso_abizaid@carleton.ca (A. Abizaid).
}

nancy ate significantly more food and had higher amounts of body fat, triglycerides levels, abnormal glycemia and reduced insulin sensibility compared to control animals (see Ainge et al., 2011 for review). In addition, these pups have higher concentrations of circulating leptin and insulin and abnormal accumulation of lipids in adipocytes in spite of consuming the same diet as control animals following weaning. These data suggest that exposure to a high fat diet somehow programs metabolism in these animals, making them more likely to become obese, supporting the notion that obesity can be programed during embryonic and fetal development (Barker, 2002; Calkins and Devaskar, 2011; Howie et al., 2009; Sloboda et al., 2009; Volpato et al., 2012).

It has been known for decades that circulating hormones such as adrenal steroids, sex steroids, and thyroid hormone exert widespread actions during critical periods of brain development (Arnold, 2017; Moog et al., 2017; Vogt and Brüning, 2013; MacKay and Abizaid, 2014; MacKay et al., 2013). Similarly, changes in the metabolic state of the mother during pregnancy and/or lactation 
can also influence brain development to facilitate the development of obesity (Bouret, 2013; Ross and Desai, 2014). For instance, caloric overload programs metabolism by altering the development of hypothalamic circuits regulating body weight and energy balance (Bouret, 2009; Sullivan et al., 2014). One critical system affected by changes in the availability of nutrients early life is the hypothalamic melanocortin system in the arcuate nucleus (ARC) (Morton et al., 2014; Schwartz et al., 2000). The expression of one component of this system, the pro-opiomelanocortin (POMC) peptide, appears to be sensitive to high fat exposure, or to early life exposure to environmental toxicants, such as bisphenol A (Fan et al., 1997; Horvath et al., 2010; MacKay et al., 2013; Rossi et al., 1998). Thus, one potential mechanism by which maternal high fat diet exposure could cause vulnerability to obesity would include alterations in the factors that control fate and/or expression of melanocortin neurons.

One such factor is Neurogenin 3 (Ngn3), a transcription factor that is expressed early in the development of the hypothalamus, and one that is associated with the expression of POMC (Ma et al., 1996; Pelling et al., 2011; Sommer et al., 1996). Interestingly, Ngn3 promotes the development of POMC neurons while inhibiting the development of NPY neurons especially on embryonic days 10-14 (Pelling et al., 2011). Another possible factor is the Mammalian achaete scute homolog-1 (Mash1), a proneural gene that when mutated, results in hypoplasia of both ARC and ventromedial nuclei in the hypothalamus. Mash1 is not required for POMC expression, but it is required for normal development of these neurons (McNay et al., 2006). Also, Mash1 knockout mice show substantial reductions in the number of both NPY and POMC expressing neurons (McNay et al., 2006). Thus, perturbations in Ngn3 and Mash1 expression may markedly alter the development of appetite regulatory neurons (Pelling et al., 2011). Retina and anterior neural fold homeobox (Rax) is a transcription factor expressed in ARC and ventromedial hypothalamus (VMH) nuclei. Its elimination in these nuclei leads to a severe loss of both VMH and ARC cellular phenotypes, demonstrating a role in fate specification (Lu et al., 2013). Rax also participates in defining rostrocaudal domains in the embryonic mouse hypothalamus (Ferran et al., 2015). The SIX homeobox 3 (Six3) gene provides necessary instructions for the formation of the forebrain and eye development. Six 3 is a transcription factor that binds to specific DNA sequences, controlling gene activation or inactivation, being crucial in embryonic development (Lagutin et al., 2003; Oliver et al., 1995).

Given the importance of these transcription factors on the development of the cells in the ARC, we reasoned that in utero exposure to high fat diets alters the expression of these transcription factors to ultimately affect the phenotype of cells in ARC and thus promote obesity. To test this hypothesis, we compared mRNA expression of these transcription factors in rat fetuses obtained from dams exposed to a control or high fat diet and sacrificed at different time points of pregnancy that encompass the development and differentiation of the hypothalamus. We also investigated whether high fat exposure during pregnancy interferes with the pattern of mRNA expression for peptides in the ARC that are known to regulate energy balance including POMC, NPY and AgRP given the potential for this diet to influence the proliferation of these cells groups early in life.

\section{Material and methods}

\subsection{Animals}

Thirty-one virgin female Wistar rats were purchased from Charles River and housed in polypropylene cages with ad libitum access to food and tap water during the whole experiment. Ani-
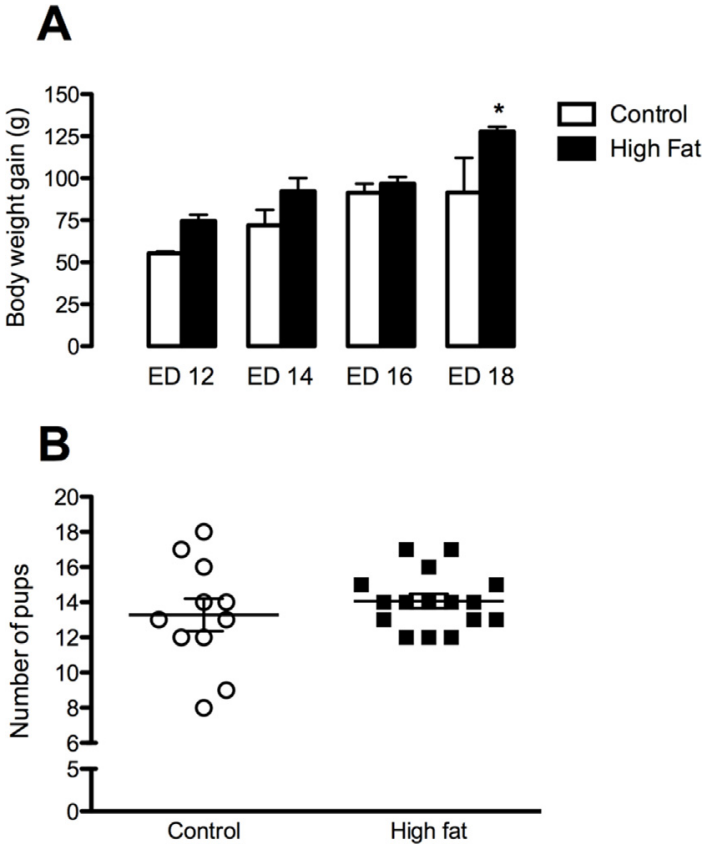

Fig. 1. Maternal body weight gain and number of embryos at time of sacrifice. Data are expressed as mean \pm S.E.M. (A) Dams body weight gain from day 0 to 12,0 to 14,0 to 16 and 0 to 18 of pregnancy in control ( $n=3$ per day) and high fat ( $n=4$ per day) groups. A two-way ANOVA, showed that dams fed a high fat diet weighed more than those fed a control diet at all time points examined and as shown by a significant effect of diet $(p<0.001)$. All rats gained weight across pregnancy as shown by a significant effect of time $(p<0.0001)$. No significant diet $\times$ time interaction $(p>0.05)$ suggested that high fat fed dams did not gain weight differently than controls across the times examined.(B) Maternal high fat diet during pregnancy did not significantly influence the number of fetuses per dam seen on the day of the laparotomy compared to those seen in control dams and as determined by a between groups $t$-test $(p>0.05)$; control $(n=11)$ and high fat $(n=16)$. The number of pups quantified in this figure comprises the total number of pups per dam regardless of the day in which the dam was killed.

mals were maintained on a 12-h light, 12-h dark cycle (lights on at 8 a.m.). All procedures were approved by Carleton University Animal Care Committee and followed the guidelines of Canadian Council on Animal Care.

To determine the day of conception, females were housed with sexually experienced males, and vaginal smears were collected daily until the presence of sperm was observed on the slide. This time point was considered day 0 of pregnancy. Pregnant females were then single housed, and immediately assigned to one of two groups: (1) high fat group $(n=16)$ in which females received a $60 \%$ fat diet since day 0 of pregnancy until the day they were sacrificed to obtain the brain of developing fetuses as described below; (2) control group $(n=15)$ that received a standard diet during the same period (one rat failed to get pregnant). Maternal body weight was measured on pregnancy day 0 and right before the dam was killed. The number of embryos per mother in the laparotomy procedure was also analyzed. For all molecular analyses, we used two pups per litter.

\subsection{Diet composition}

The high fat diet was a purified diet, which had $5.1 \mathrm{kcal} / \mathrm{g}$, with $60.3 \%$ of calories derived from fat (18.4\% from protein and $21.3 \%$ from carbohydrates). Its composition had casein, L-cystine, maltodextrin, sucrose, lard, soybean oil, cellulose, mineral mix, calcium phosphate, vitamin mix, choline bitartrate and blue food color (TD.06414, Harlan Laboratories). The standard lab chow utilized in this study was composed by $2.9 \mathrm{kcal} / \mathrm{g}$, with $13 \%$ of calories derived from fat (20\% from protein and $67 \%$ from carbohydrates). 
A

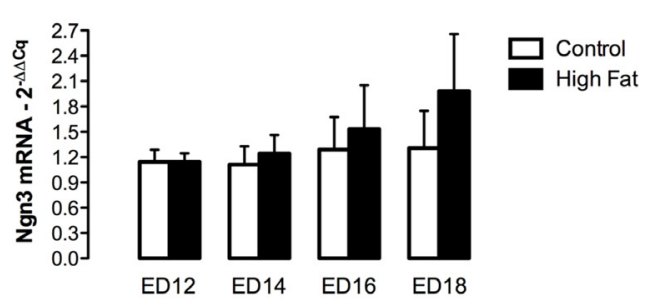

C

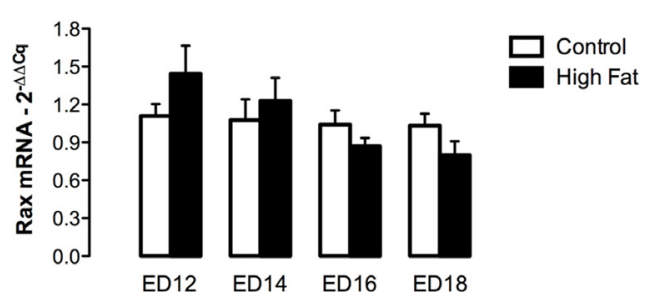

B
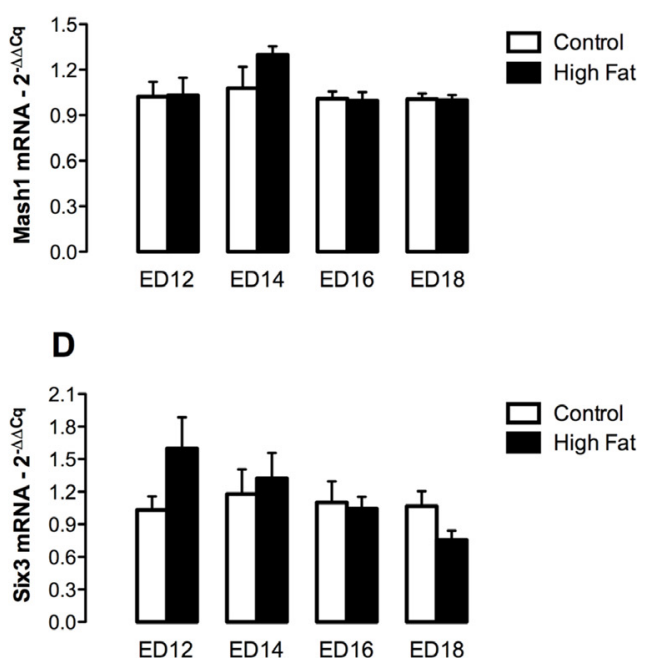

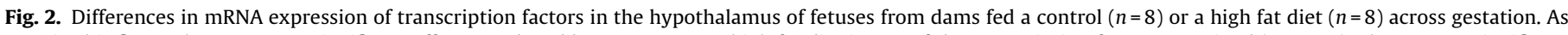

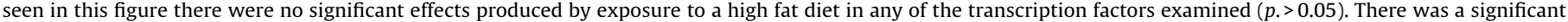
main effect for time, showing that Rax mRNA expression decreased from ED 12 to ED 18 ( $p<0.05)$. Data are expressed as mean \pm S.E.M. Two-way ANOVA.

It contained wheat middlings, ground wheat, ground corn, corn gluten meal, calcium carbonate, soybean oil, dicalcium phosphate, L-lysine, iodized salt, DL-methionine, vitamin E acetate, magnesium oxide, choline chloride, menadione sodium bisulfite, calcium pantothenate, manganous oxide, ferrous sulfate, thiamin mononitrate, zinc oxide, niacin, copper sulfate, riboflavin, vitamin A acetate, pyridoxine hydrochloride, calcium iodate, vitamin B12 supplement, folic acid, biotin, vitamin D3 supplement, cobalt carbonate.

\subsection{Embryonic tissue collection}

Four pregnant females from each group were sacrificed by $\mathrm{CO}_{2}$ asphyxiation on days $12,14,16$ and 18 of pregnancy to obtain fetuses via laparotomy. As soon as the dams were dead, an incision was made across the abdomen, and the uterus was exteriorized and fetuses were extracted and rapidly decapitated. The entire head of embryos on embryonic days (ED) 12 and 14, and the extracted fetal brains from fetuses collected on days 16 and 18 of pregnancy were used. Half of the embryos from each litter were flash frozen in TRI$\mathrm{zol}\left(\right.$ Invitrogen $\left.{ }^{\circledR}\right)$ solution and stored in deep freezer $\left(-80^{\circ} \mathrm{C}\right)$. Of these, two pups per litter were used for RNA extraction and qPCR analyses for a total of 8 pairs of pups per experimental group at each of the time points. We considered each pair as an $n=1$.

\subsection{Gene expression analyses}

Gene expression was evaluated for Neurogenin 3 (Ngn3), Mammalian achaete scute homolog-1 (Mash1), Retinal and anterior neural fold homeobox (Rax), SIX homeobox 3 (Six3), Pro-opiomelanocortin (POMC), Neuropeptide Y (NPY) and Agoutirelated peptide (AgRP), Protein convertase 1/3 (PC1), Protein convertase 2 (PC2), Melanocortin-4 receptor (MC4R) and Suppressor of cytokine signaling 3 (SOCS3).

\subsubsection{Reverse transcribed PCR assay (RT-PCR)}

Embryos samples were homogenized in $1 \mathrm{ml}$ TRIzol using the method provided by the manufacturer (Invitrogen ${ }^{\circledR}$ ) and reverse transcribed using the iScript ${ }^{\mathrm{TM}}$ cDNA synthesis kit (Bio-Rad Laboratories) as indicated by the manufacturer as well. Samples were then stored in $-20^{\circ} \mathrm{C}$ for future use.

\subsubsection{Quantitative real-time $P C R$ ( $q P C R$ )}

All samples were tested before they were analyzed by qPCR in order to measure the integrity of the RNA extracted from each embryo. qPCR was performed in a CFX Connect ${ }^{\mathrm{TM}}$ RealTime PCR Detection System (Bio-Rad Laboratories) using iQ SYBR Green Super Mix (Bio-Rad Laboratories). The primer sequences for Ngn3 were: sense 5'-GCAGAGCAGATAAAGCGTGC3', antisense 5'-TCGCCTGGAGTAAATTGCGT-3'. For Mash1: sense 5'-TCGGCGGTCGAATACATCC-3', antisense 5'-CCGCCATAGAGTTCAAGTCGT-3'. For Rax: sense $5^{\prime}$-AGCGGGACCTTCAGTTTGG-3', antisense 5'CTTGGTCTTCGTGCCGTACTC-3'. For Six3: sense 5'-TCAGCAGAGTCACCGTCCAC-3', antisense 5' TGGAGGTTACCGAGAGGATCG-3'. For POMC: sense 5'-CCTGTGAAGGTGTACCCCAATGTC-3', antisense $5^{\prime}$ CACGTTCTTGATGATGGCGTTC-3'. For NPY: sense 5'-CCCGCCCGCCATGATGCTAGG-3', antisense 5'CCGCCCGGATTGTCCGGCTTG-3'. For AgRP: sense 5'-AGAGTTCTCAGGTCTAAGTCT-3', antisense 5'CTTGAAGAAGCGGCAGTAGCACGT-3'. For PC1: sense 5'-CGAAGAGGCAGTTTGTCAATGAATGG-3', antisense 5'-ATCATCAGATAACCTCTTAGTG-3'. For PC2: sense $\quad 5^{\prime}$-CCTTTGCAGAAGGCCTGTACCAC-3', antisense 5'-AGCCCAGGAGTCCCGTCAGCTTGC-3'. For MC4R: sense 5'-AACATTCTAGTGATCGTGGC-3', antisense 5'-CATAATGTTATGGTACTGGAGCGCg-3'. For SOCS3: sense 5'-CTTTACCACCGACGGAACCT-3', antisense $5^{\prime}$-CCGTTGACAGTCTTCCGACA-3'. For GAPDH: sense 5'-AAGATGGTGAAGGTCGGTGT-3', antisense $5^{\prime}$ CTTGCCGTGGTAGAGTCAT-3'.

The qPCR conditions utilized were as follow: Step $1-30 \mathrm{~s}$ at $95^{\circ} \mathrm{C}$; Step $2-10$ s at $95^{\circ} \mathrm{C}, 30$ s at $57^{\circ} \mathrm{C}$ and then 20 s at $72{ }^{\circ} \mathrm{C}$; step 2 was repeated 45 times. Step $3-60$ s at $95^{\circ} \mathrm{C}$; Step $4-60$ s at $55^{\circ} \mathrm{C}$; Step $5-30 \mathrm{~s}$ at $55^{\circ} \mathrm{C}$ (41 repeats). $\mathrm{C}(\mathrm{q})$ values were determined automatically by CFX Manager ${ }^{\mathrm{TM}}$ Software (Bio-Rad Laboratories). Quantification of transcripts of interest relative to the internal housekeeping control gene GAPDH was determined using the $2^{-\Delta \Delta \mathrm{Cq}}$ method (Bustin et al., 2009; Schmittgen and Livak, 2008). 
A

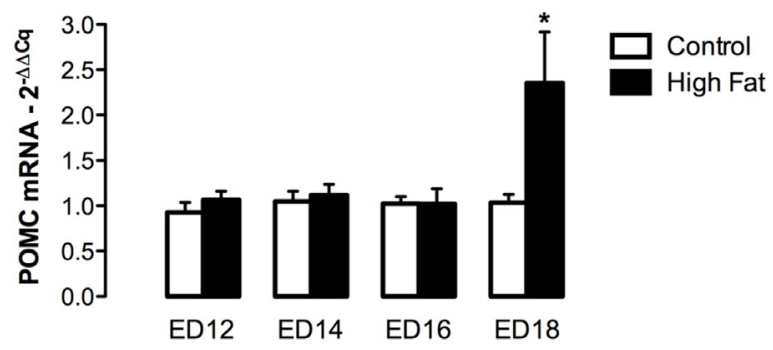

B

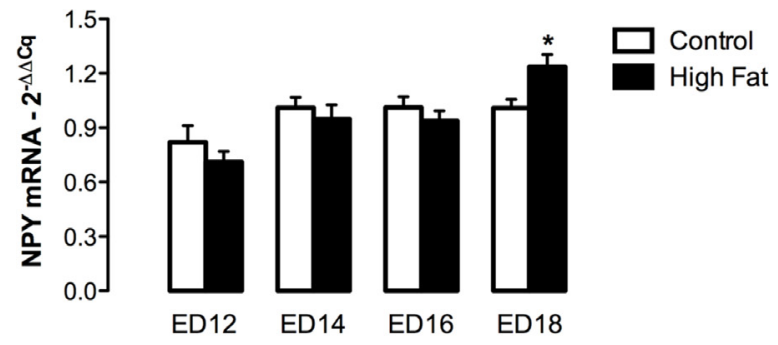

C

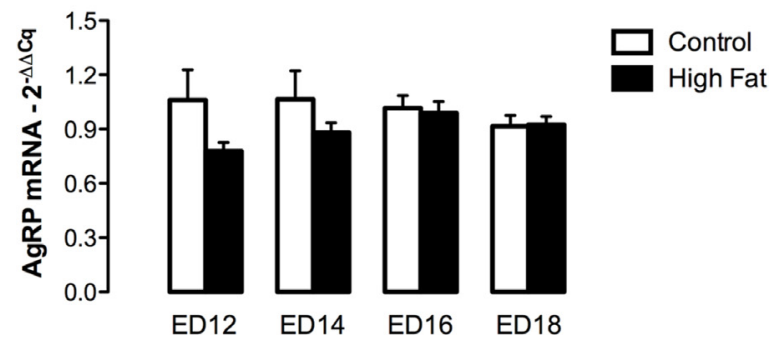

Fig. 3. mRNA expression of peptides involved in food intake control and energy balance in control and high fat animals ( $n=8 /$ group) and POMC staining in the ARC nucleus from fetuses on ED 18. (A) POMC expression: significant effects of diet $(p<0.05)$, time $(p<0.01)$ and interaction in between diet $\times$ time $(p<0.05)$. * $p<0.001$ compared to control group on ED18, Bonferroni post hoc; (B) NPY expression: significant effect of time $(p<0.0001)$ and interaction in between diet $\times$ time $(p<0.05) .{ }^{*} p<0.05$ compared to control group on ED18, Student's $t$-test; (C) AgRP mRNA expression. Data are expressed as mean \pm S.E.M.; Two-way ANOVA.

\subsection{Statistics}

Data were analyzed using two-way ANOVA with embryonic day (time) and diet as factors. Bonferroni or Student's $t$-test were used as post hoc tests when applicable. Statistics were performed on GraphPad Prism 5.0 or SPSS Statistics 18 software.

A significance criterion was set at $\alpha=0.05$.

\section{Results}

Throughout pregnancy, there was a significant effect of time in body weight gain of the dams as expected $(p<0.0001$; $F(3,19)=15.31-$ Fig. 1A). Also, there was a significant effect of the $\operatorname{diet}(p=0.0004 ; F(1,19)=18.39)$, where the high fat mothers on day 18 of pregnancy were heavier than controls (Fig. 1A). There was no difference in between the number of pups born per mother from each group (Fig. 1B).

Of all transcription factors examined, we only detected a significant effect of time on Rax mRNA expression, where Rax expression decreased across embryonic age, with ED 12 showing the highest level of expression and ED 18 showing the lowest level of expression (Fig. $2 C-p=0.044 ; F(3,55)=2.874$ ). Neither significant main effects for diet nor any interaction effects were detected in the analyses for any of the transcription factors examined ( $p>0.05$; Fig. 2A, B and D).

Interestingly, our analyses revealed that the hypothalamus of rat fetuses obtained from dams fed a high fat diet showed higher POMC expression than those of fetuses collected from dams eating the control diet as determined by a significant interaction effect $(p<0.05 ; F(3,55)=3.806$; Fig. 3A). This effect was driven primarily by group differences found on ED 18, where POMC expression was higher in pups taken from high fat diet fed dams than in those taken from controls. Similarly, NPY expression was also significantly elevated in the brains from fetuses taken from high fat exposed females on ED 18 compared to rats taken from chow fed dams on the same day of embryonic development (interaction effect $p<0.04 ; F(3,55)=2.913$; Fig. 3B). No differences in AgRP mRNA expression were observed ( $p>0.05$; Fig. $3 C$ ).

To analyze if the mechanisms that transform POMC into other functional peptides like $\alpha$-MSH, ACTH or $\beta$-endorphin were affected by high fat diet exposure, we also examined differences in the expression of Protein Convertase 1 (PC1) and Protein Convertase 2 (PC2) in the samples from pups raised by control of high fat diet fed dams. Results show that there were no differences in the expression of PC1 or PC2 in embryos from control and HF dams at any gestation time point evaluated in the experiment $(p>0.05$; Fig. 4A and $\mathrm{B}$ ).

Interestingly, exposure to the high fat diet led to a significant increase in the mRNA expression of the Suppressor of Cytokine Signaling 3 (SOCS3) gene, a gene associated with leptin sensitivity, on ED12 (interaction effect $p<0.05 ; F(3,53)=3.771$; time effect $p<0.001 ; F(3,53)=6.305$; Fig. $4 C)$. In this same day of embryonic development (ED12), the mRNA expression level of melanocortin4 receptor (MC4R) was higher in the fetuses from high fat dams compared to the offspring from mothers given regular chow (interaction effect $p<0.05 ; F(3,53)=3.379$; time effect $p<0.001$; $F(3,53)=6.0$; Fig. 4D). These differences, however, were transient and disappeared by ED14.

\section{Discussion}

Maternal nutrition plays an important role in the metabolic programing of their offspring's metabolism. In this study, we showed that maternal exposure to a high fat diet during pregnancy leads to increased expression of POMC and NPY mRNA in comparison to that of pups taken from moms with access to a regular chow diet. Furthermore, we observed that the changes in POMC mRNA are associated with an increase in POMC protein expression. We also determined that neither of these changes were due to changes in the mRNA expression of transcription factors associated with the development of hypothalamic nuclei (MacKay and Abizaid, 2014), nor in altered ability of the hypothalamus to respond to leptin, or to produce $\alpha-\mathrm{MSH}$, a peptide derivative of the POMC peptide that has anorectic effects and that stimulates metabolic rate.

The differences in POMC and NPY expression were unlikely due to differences between the dams. All dams exposed to the high fat diet gained similar amount of weight during pregnancy. This increase in weight was significant compare to the weight gain of controls and in spite of the relatively short period of high fat exposure (18 days). In addition, the total number of pups at the moment of the laparotomy in each group was similar, which leads us to conclude that the higher weight of the dams was not because they had more pups. We can therefore infer that the effects observed are associated with hormonal and/or metabolic parameters produced by the high fat diet on the dams (Cerf et al., 2005; Tamashiro et al., 2009). 
A

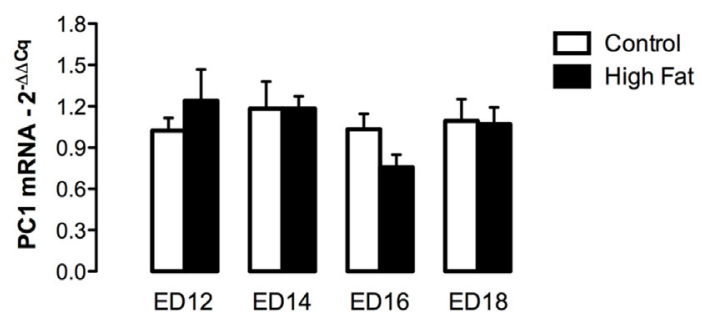

\section{C}

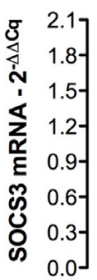

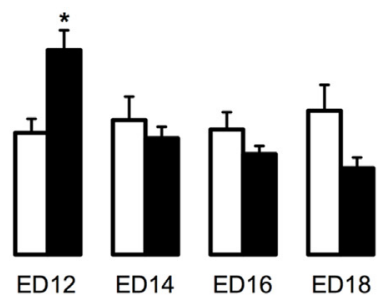

B

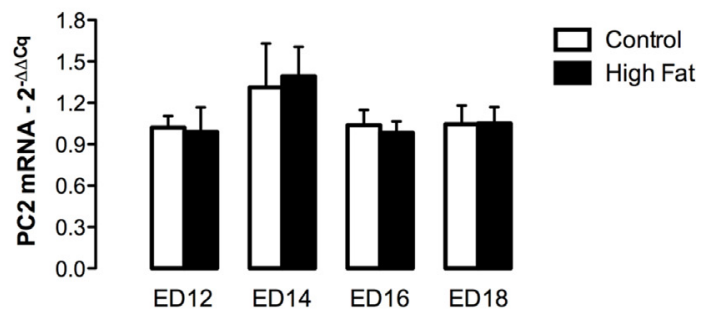

D
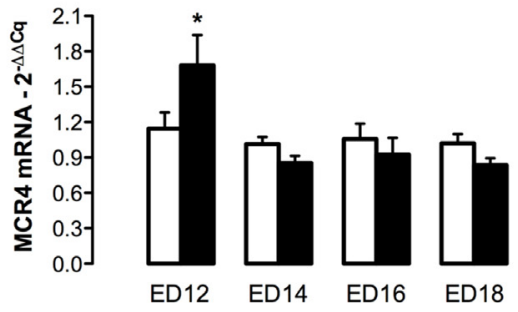

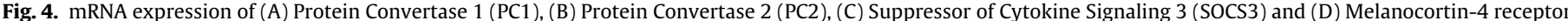

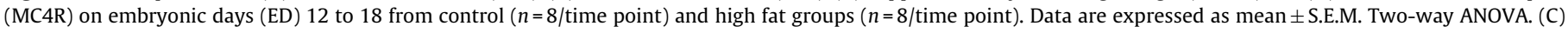

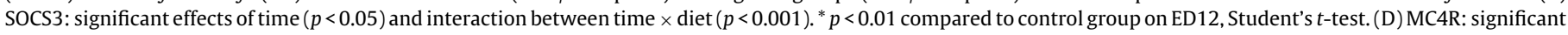
effects of time $(p<0.001)$ and interaction time $\times \operatorname{diet}(p<0.05) ;{ }^{*} p<0.05$ compared to control on ED12, Student's $t$-test.

The increase in POMC and NPY expression detected in the brains of E18 pups taken from dams fed a high fat diet is somewhat paradoxical. Indeed, one would expect that POMC expression would be decreased as it does in adult animals that are chronically exposed to high fat diets (Cifani et al., 2015; Desai et al., 2016). Nevertheless, our data are consistent with data of others showing that rat pups whose mother was exposed to a high fat diet showed increased POMC and NPY mRNA expression in the ARC twenty days after birth (Chen and Morris, 2009). In addition, POMC mRNA expression is elevated in lambs taken from over-nourished ewes (Muhlhausler et al., 2006). Furthermore, in situ hybridization analyses of hypothalamic ARC nuclei from Japanese macaques fetuses harvested from high fat fed mothers early in their third trimester of pregnancy also showed increased POMC mRNA expression (Grayson et al., 2010). At this time, the factors that mediate the up-regulation of POMC expression remain to be determined. Yet it is clear that the high fat diet exposure does not have any major impact on the expression of transcription factors that are closely associated with the development and differentiation of cells within hypothalamic nuclei regulating energy homeostasis. Thus, while there were some variations in the expression of Ngn3, Rax and Six 3 across the time points that we examined, these were not affected by maternal diet. While Mash-1 has been reported to be reduced by maternal high fat diet exposure in the hypothalamus of newborn rat pups (Desai et al., 2016), we did not find any changes in Mash-1 expression at any time point that we examined. Given these data, it is likely that other factors are being affected by maternal exposure to the high fat diet to increase POMC mRNA expression.

Given that, once translated into protein, the POMC peptide is cleaved into several different peptides that include $\alpha$-melanocyte-stimulating peptide $(\alpha-\mathrm{MSH}), \beta$-Endorphin and adrenocorticotropin hormone $(\mathrm{ACTH})$, one could argue that the high fat diet could influence the enzymes that cleave POMC into these three peptides. This would be critical if the reduction was specific to decrease $\alpha$-MSH, a peptide known for its potent anorectic effects. Nevertheless, we did not observe changes in the expression of PC1 or PC2, both enzymes important for the post-translational modification of the POMC peptide into $\alpha-\mathrm{MSH}$ (Wardlaw, 2011).
One factor that could be influencing POMC expression is circulating maternal leptin. Leptin, a hormone that stimulates POMC expression, may be increased in dams exposed to the high fat diet due to maternal leptin insensitivity (Tamashiro et al., 2009). Thus, while the dam may not respond to high leptin, the fetuses may still remain sensitive to maternal leptin and as such show high levels of POMC expression. Interestingly, we observed higher mRNA expression levels of SOCS3, a molecule that inhibits the activity of the leptin receptor reducing leptin sensitivity, in the hypothalamus of fetuses harvested from dams fed a high fat diet on the ED12, however this difference disappeared by ED14, and SOCS3 expression was the same on the day that POMC is elevated in pups harvested from dams fed the high fat diet (ED18). Moreover, the same was observed in the expression of the receptors that binds $\alpha-\mathrm{MSH}$, the melanocortin-4 receptor (MC4R). This supports the notion that maternal high fat diet exposure during pregnancy does not have a major impact in the expression of transcripts associated with leptin sensitivity in the fetal hypothalamus, nor that of enzymes important for the synthesis of $\alpha$-MSH. Furthermore, it does not seem to influence the expression of the MC4R, a gene important for the full effects of $\alpha-\mathrm{MSH}$, at least not during gestation.

The current study examined the effects of maternal exposure to a high fat diet high fat diet during pregnancy, whereas the majority of studies in the field have used models where the mothers are exposed to the high fat diets for a time period prior to mating. While fewer studies have focused on the effects of high fat diets given only during pregnancy, those that have demonstrate that this exposure is also associated with an obese and insulin resistant phenotype in the offspring of exposed dams (Sun et al., 2013; Dearden and Balthasar, 2014). Therefore, one could argue that the susceptibility for obesity in pups born to mothers fed a high fat diet only during pregnancy is not due to the transcription factors examined. Indeed, transcription factors such as the Oligodendrocyte transcription factor 1 (Olig1), Nescient helix-loop-helix (Nhlh) transcription factor and the LIM-homeobox transcription factor Islet 1 are expressed in POMC neurons of developing embryos (Nasif et al., 2015; Good et al., 1997; Peng et al., 2012). It is therefore possible that the effects of the high fat diet on POMC and NPY gene expression observed in 
this study are due to changes in transcription factors other than those analyzed. Alternatively, it is possible that the transcription factors examined in this study are altered by more prolonged exposure to the high fat diet. Indeed, some have suggested that while exposure to a high fat diet exclusively during pregnancy results in similar obese phenotype than that seen in animals whose mother was exposed to a high fat diet prior to pregnancy, the underlying mechanisms may actually differ (Howie et al., 2013).

In sum, it is clear that exposing a dam to a high fat diet during pregnancy was not effective in altering critical transcripts associated with the development of hypothalamic cell groups important for the regulation of feeding and energy balance. While the expression of POMC and NPY was increased by this treatment, the treatment did not influence the expression of transcripts associated with leptin signaling, nor the expression of mRNA for enzymes required for the production of $\alpha-\mathrm{MSH}$. Furthermore, this treatment did not affect the expression of $\alpha-\mathrm{MSH}$, at least not at the transcriptional level. This suggests that, either our current paradigm was not effective in the development of the circuits that regulate metabolism, or that other factors not explored here are affected. The potential for the latter argument is high given the complexity of the factors implicated in the regulation of food intake and energy balance, as well as the developmental factors recruited during this phase of embryonic development. It is important to note that others have shown clear long lasting effects of high fat diet exposure on programing offspring metabolism using protocols where the high fat diet exposure precedes pregnancy by 4-6 weeks (Chen and Morris, 2009; Desai et al., 2014; Morris and Chen, 2009; White et al., 2009). Nevertheless, our intention here was to isolate effects caused by high exposure during pregnancy alone, given that some studies show that exposure to high fat diets during pregnancy do result in offspring that are more vulnerable to develop obesity (Dearden and Balthasar, 2014; Sun et al., 2012; Howie et al., 2013).

It is important to note that the effects observed are seen only after 2-3 weeks of maternal exposure, given the short duration of gestation in rodents. In humans gestation is much longer, and high fat exposure may have a stronger impact simply because of the prolonged time of exposure. Nevertheless, our comparative approach allows to detect specific windows that are known to be important for hypothalamic development, and could provide for mechanisms that apply to humans. Given this, and the fact that there are effects in hypothalamic peptide expression even after only a few days of exposure, suggest that high fat diets may have a profound impact on the development of circuits that regulate food intake and metabolism in humans.

\section{Conflict of interest statement}

The authors declare no conflicts of interest.

\section{Acknowledgments}

We would like to thank MSc. Trevor Rodrigues for all the management support. This work was supported by Fundação de Amparo à Pesquisa do Estado de São Paulo (FAPESP, \#2012/07378-6 and \#2014/06980-0 to MOK) and a discovery grant from the Natural Sciences and Engineering Research Council of Canada (NSERC, \#341538).

\section{Appendix A. Supplementary data}

Supplementary material related to this article can be found, in the online version, at http://dx.doi.org/10.1016/j.ijdevneu.2017.03. 004.

\section{References}

Ainge, H., Thompson, C., Ozanne, S.E., Rooney, K.B., 2011. A systematic review on animal models of maternal high fat feeding and offspring glycaemic control. Int. J. Obes. 35, 325-335, http://dx.doi.org/10.1038/ijo.2010.149, 2005.

Arnold, A.P., 2017. A general theory of sexual differentiation. J. Neurosci. Res. 95, 291-300.

Barker, D.J., 2002. Fetal programming of coronary heart disease. Trends. Endocrinol. Metab. 13, 364-368, S1043276002006896 [pii].

Bouret, S.G., 2009. Early life origins of obesity: role of hypothalamic programming. J. Pediatr. Gastroenterol. Nutr. 48 (Suppl 1), S31-S38, http://dx.doi.org/10. 1097/MPG.0b013e3181977375.

Bouret, S.G., 2013. Organizational actions of metabolic hormones. Front. Neuroendocrinol. 34, 18-26, http://dx.doi.org/10.1016/j.yfrne.2013.01.001.

Bustin, S.A., Benes, V., Garson, J.A., Hellemans, J., Huggett, J., Kubista, M., Mueller, R., Nolan, T., Pfaffl, M.W., Shipley, G.L., Vandesompele, J., Wittwer, C.T., 2009. The MIQE guidelines: minimum information for publication of quantitative real-time PCR experiments. Clin. Chem. 55, 611-622, http://dx.doi.org/10. 1373/clinchem.2008.112797.

Calkins, K., Devaskar, S.U., 2011. Fetal origins of adult disease. Curr. Prob. Pediatr. Adolesc. Health Care 41, 158-176, http://dx.doi.org/10.1016/j.cppeds.2011.01. 001.

Cerf, M.E., Williams, K., Nkomo, X.I., Muller, C.J., Du Toit, D.F., Louw, J., Islet, S.A.W., 2005. Islet cell response in the neonatal rat after exposure to a high-fat diet during pregnancy. Am. J. Physiol. Regul. Integr. Comp. Physiol. 288, 1122-1128, http://dx.doi.org/10.1152/ajpregu.00335.2004.

Chen, H., Morris, M.J., 2009. Differential responses of orexigenic neuropeptides to fasting in offspring of obese mothers. Obesity (Silver Spring) 17, 1356-1362, http://dx.doi.org/10.1038/oby.2009.56.

Cifani, C., Micioni Di Bonaventura, M.V., Pucci, M., Giusepponi, M.E., Romano, A., Di Francesco, A., Maccarrone, M., D'Addario, C., 2015. Regulation of hypothalamic neuropeptides gene expression in diet induced obesity resistant rats: possible targets for obesity prediction? Front. Neurosci. 9, 187, http://dx.doi.org/10. 3389/fnins.2015.00187.

Dearden, L., Balthasar, N., 2014. Sexual dimorphism in offspring glucosensitive hypothalamic gene expression and physiological responses to maternal high-fat diet feeding. Endocrinology 155, 2144-2154.

Desai, M., Jellyman, J.K., Han, G., Beall, M., Lane, R.H., Ross, M.G., 2014. Maternal obesity and high-fat diet program offspring metabolic syndrome. Am. J. Obstet. Gynecol. 211, http://dx.doi.org/10.1016/j.ajog.2014.03.025, 237.e1-237.e13.

Desai, M., Han, G., Ross, M.G., 2016. Programmed hyperphagia in offspring of obese dams: altered expression of hypothalamic nutrient sensors, neurogenic factors and epigenetic modulators. Appetite 99, 193-199, http://dx.doi.org/10.1016/j. appet.2016.01.023.

Fan, W., Boston, B.A., Kesterson, R.A., Hruby, V.J., Cone, R.D., 1997. Role of melanocortinergic neurons in feeding and the agouti obesity syndrome. Nature 385, 165-168.

Ferran, J.L., Puelles, L., Rubenstein, J.L.R., 2015. Molecular codes defining rostrocaudal domains in the embryonic mouse hypothalamus. Front. Neuroanat. 9, 46, http://dx.doi.org/10.3389/fnana.2015.00046.

Good, D.J., Porter, F.D., Mahon, K.A., Parlow, A.F., Westphal, H., Kirsh, I.R., 1997. Hypogonadism and obesity in mice with a targeted deletion of the Nhlh gene. Nat. Genet. 15, 397-401.

Grayson, B.E., Kievit, P., Smith, M.S., Grove, K.L., 2010. Critical determinants of hypothalamic appetitive neuropeptide development and expression: species considerations. Front. Neuroendocrinol., http://dx.doi.org/10.1016/j.yfrne. 2009.10.001.

Horvath, T.L., Sarman, B., Garciía-Cáceres, C., Enriori, P.J., Sotonyi, P., Shanabrough, M., Borok, E., Argente, J., Chowen, J.A., Perez-Tilve, D., Pfluger, P.T., Brönneke, H.S., Levin, B.E., Diano, S., Cowley, M.A., Tschöp, M.H., 2010. Synaptic input organization of the melanocortin system predicts diet-induced hypothalamic reactive gliosis and obesity. Proc. Natl. Acad. Sci. U.S.A. 107, 14875-14880, http://dx.doi.org/10.1073/pnas.1004282107.

Howie, G.J., Sloboda, D.M., Kamal, T., Vickers, M.H., 2009. Maternal nutritional history predicts obesity in adult offspring independent of postnatal diet. J. Physiol. 587, 905-915, http://dx.doi.org/10.1113/jphysiol.2008.163477.

Howie, G.J., Sloboda, D.M., Raynolds, C.M., Vickers, M.H., 2013. Timing of maternal exposure to a high fat diet and development of obesity and hyperinsulinemia in male rat offspring: same metabolic phenotype, different developmental pathways? J. Nutr. Metab. 2013, 517384, http://dx.doi.org/10.1155/2013/ 517384.

Lagutin, O.V., Zhu, C.C., Kobayashi, D., Topczewski, J., Shimamura, K., Puelles, L., Russell, H.R.C., McKinnon, P.J., Solnica-Krezel, L., Oliver, G., 2003. Six3 repression of Wnt signaling in the anterior neuroectoderm is essential for vertebrate forebrain development. Genes Dev. 17, 368-379, http://dx.doi.org/ $10.1101 /$ gad.1059403.

Lu, F., Kar, D., Gruenig, N., Zhang, Z.W., Cousins, N., Rodgers, H.M., Swindell, E.C., Jamrich, M., Schuurmans, C., Mathers, P.H., Kurrasch, D.M., 2013. Rax is a selector gene for mediobasal hypothalamic cell types. J. Neurosci. 33, 259-272, http://dx.doi.org/10.1523/JNEUROSCI.0913-12.2013.

Ma, Q., Kintner, C., Anderson, D.J., 1996. Identification of neurogenin, a vertebrate neuronal determination gene. Cell 87, 43-52.

MacKay, H., Abizaid, A., 2014. Embryonic development of the hypothalamic feeding circuitry: transcriptional, nutritional, and hormonal influences. Mol. Metab. 3, 813-822, http://dx.doi.org/10.1016/j.molmet.2014.09.004. 
MacKay, H., Patterson, Z.R., Khazall, R., Patel, S., Tsirlin, D., Abizaid, A., 2013. Organizational effects of perinatal exposure to bisphenol- $a$ and diethylstilbestrol on arcuate nucleus circuitry controlling food intake and energy expenditure in male and female CD-1 mice. Endocrinology 154 1465-1475, http://dx.doi.org/10.1210/en.2012-2044.

McNay, D.E.G., Pelling, M., Claxton, S., Guillemot, F., Ang, S.-L., 2006. Mash1 is required for generic and subtype differentiation of hypothalamic neuroendocrine cells. Mol. Endocrinol. 20, 1623-1632, http://dx.doi.org/10. 1210/me.2005-0518.

Moog, M.K., Etringer, S., Heim, C., Wadhwa, P.D., Kathmann, N., Buss, C., 2017. Influence of maternal thyroid hormones during gestation on fetal development. Neuroscience 342, 68-100.

Morris, M.J., Chen, H., 2009. Established maternal obesity in the rat reprograms hypothalamic appetite regulators and leptin signaling at birth. Int. J. Obes. (Lond.) 33, 115-122, http://dx.doi.org/10.1038/ijo.2008.213.

Morton, G.J., Meek, T.H., Schwartz, M.W., 2014. Neurobiology of food intake in health and disease. Nat. Rev. Neurosci. 15, 367-378, http://dx.doi.org/10.1038/ nrn3745.

Muhlhausler, B.S., Adam, C.L., Findlay, P.A., Duffield, J.A., McMillen, I.C., 2006. Increased maternal nutrition alters development of the appetite-regulating network in the brain. FASEB J. 20, 1257-1259, http://dx.doi.org/10.1096/fj.055241 fje.

Nasif, S., de Souza, F.S.J., Gonzales, L.E., Yamashita, M., Orquera, D.P., Low, M.J., Rubinstein, M., 2015. Islet 1 specifies the identity of hypothalamic melanocortin neurons and is critical for normal food intake and adiposity in adulthood. Proc. Natl. Acad. Sci. U.S.A. 112 (15), E1861-E1870.

Oliver, G., Mailhos, A., Wehr, R., Copeland, N.G., Jenkins, N.A., Gruss, P., 1995. Six3, a murine homologue of the sine oculis gene, demarcates the most anterior border of the developing neural plate and is expressed during eye development. Development 121, 4045-4055.

Pelling, M., Anthwal, N., McNay, D., Gradwohl, G., Leiter, A.B., Guillemot, F., Ang, S.L., 2011. Differential requirements for neurogenin 3 in the development of POMC and NPY neurons in the hypothalamus. Dev. Biol. 349, 406-416, http:// dx.doi.org/10.1016/j.ydbio.2010.11.007.

Peng, C.-Y., Mukhopadhyay, A., Jarrett, J.C., Yoshikawa, K., Kessler, J.A., 2012. BMP receptor 1 A regulates development of hypothalamic circuits critical for feeding behavior. J. Neurosci. 32 (48), 17211-17224.

Poston, L., 2012. Gestational weight gain: influences on the long-term health of the child. Matern. Obes. Pregnancy 15, 252-257, http://dx.doi.org/10.1007/978-3642-25023-1.

Ross, M.G., Desai, M., 2014. Developmental programming of appetite/satiety. Ann. Nutr. Metab. 64, 36-44, http://dx.doi.org/10.1159/000360508.

Rossi, M., Kim, M.S., Morgan, D.G.A., Small, C.J., Edwards, C.M.B., Sunter, D., Abusnana, S., Goldstone, A.P., Russel, S.H., Stanley, S.A., Smith, D.M., Yagaloff, K., Ghatei, M.A., Bloom, S.R., 1998. A C-terminal fragment of Agouti-related protein increases feeding and antagonizes the effect of alpha-melanocyte stimulating hormone in vivo. Endocrinology 139, 4428-4431.
Samuelsson, A.M., Matthews, P.A., Argenton, M., Christie, M.R., McConnell, J.M Jansen, E.H.J.M., Piersma, A.H., Ozanne, S.E., Twinn, D.F., Remacle, C., Rowlerson, A., Poston, L., Taylor, P.D., 2008. Diet-induced obesity in female mice leads to offspring hyperphagia, adiposity, hypertension, and insulin resistance: a novel murine model of developmental programming. Hypertension 51, 383-392, http://dx.doi.org/10.1161/HYPERTENSIONAHA.107.101477.

Schmittgen, T.D., Livak, K.J., 2008. Analyzing real-time PCR data by the comparative CT method. Nat. Protoc. 3, 1101-1108, http://dx.doi.org/10.1038/nprot.2008. 73.

Schwartz, M.W., Woods, S.C., Porte, D., Seeley, R.J., Baskin, D.G., 2000. Central nervous system control of food intake. Nature 404, 661-671, http://dx.doi.org/ $10.1038 / 35007534$

Sloboda, D.M., Howie, G.J., Pleasants, A., Gluckman, P.D., Vickers, M.H., 2009. Preand postnatal nutritional histories influence reproductive maturation and ovarian function in the rat. PLoS ONE 4,1-8, http://dx.doi.org/10.1371/journal. pone.0006744.

Sommer, L., Ma, Q., Anderson, D.J., 1996. Neurogenins, a novel family of atonal-related bHLH transcription factors, are putative mammalian neuronal determination genes that reveal progenitor cell heterogeneity in the developing CNS and PNS. Mol. Cell. Neurosci. 8, 221-241, http://dx.doi.org/10. 1006/mcne.1996.0060.

Sullivan, E.L., Nousen, E.K., Chamlou, K.A., 2014. Maternal high fat diet consumption during the perinatal period programs offspring behavior. Physiol. Behav. 123, 236-242, http://dx.doi.org/10.1016/j.physbeh.2012.07.014.

Sun, B., Purcell, R.H., Terrillion, C.E., Yan, J., Moran, T.H., Tamashiro, K.L., 2012. Maternal high-fat diet during gestation or suckling differentially affects offspring leptin sensitivity and obesity. Diabetes 61, 2833-2841.

Sun, B., Liang, N.-C., Ewald, E.R., Purcell, R.H., Boersma, G.J., Yan, J., Moran, T.H., Tamashiro, K.L.K., 2013. Early post-weaning exercise improves central leptin sensitivity in offspring of rat dams fed high-fat diet during pregnancy and lactation. Am. J. Physiol., Regul., Integr. Comp. Physiol 305, R1076-R1084.

Tamashiro, K.L.K., Terrillion, C.E., Hyun, J., Koenig, J.I., Moran, T.H., 2009. Prenatal stress or high-fat diet increases susceptibility to diet-induced obesity in rat offspring. Diabetes 58, 1116-1125, http://dx.doi.org/10.2337/db08-1129.

Vogt, M.C., Brüning, J.C., 2013. CNS insulin signaling in the control of energy homeostasis and glucose metabolism - from embryo to old age. Trends Endocrinol Metab. 24, 76-84.

Volpato, A.M., Schultz, A., Magalha es-Da-Costa, E., Correia, M.L.D.G., Águila, M.B., Mandarim-De-Lacerda, C.A., 2012. Maternal high-fat diet programs for metabolic disturbances in offspring despite leptin sensitivity. Neuroendocrinology 96, 272-284, http://dx.doi.org/10.1159/000336377.

Wardlaw, S.L., 2011. Hypothalamic proopiomelanocortin processing and the regulation of energy balance. Eur. J. Pharmacol. 660, 213-219, http://dx.doi. org/10.1016/j.ejphar.2010.10.107.

White, C.L., Purpera, M.N., Morrison, C.D., 2009. Maternal obesity is necessary for programming effect of high-fat diet on offspring. Am. J. Physiol. Regul. Integr Comp. Physiol. 296, R1464-R1472, http://dx.doi.org/10.1152/ajpregu.91015. 2008. 